\title{
INFLUENCE OF FERMENTATION CONDITIONS ON THE CONTENT OF PHENOLIC COMPOUNDS, ANTHOCYANINS AND THE SPECTRAL CHARACTERISTICS OF CABERNET SAUVIGNON WINES
}

\section{Yoncheva Tatyana}

Institute of Viticulture and Enology, Pleven, Bulgaria

Received: 25. 6. 2019 Revised: 18.11.2019 Published: 30.11.2019

The wine characteristics have been determined by the variety potential and specificity, but also by the yeast strain carrying out the alcoholic fermentation. Phenolic components and anthocyanins play a significant role in the formation of the organoleptic wine qualities, especially of red wines. The yeast affects the colour of the wine mainly with the extracellular $\beta$-glucosidase they produce. The objective of the study was to investigate the influence of the technological factors yeast strain, temperature and inoculum amount of yeast culture on the variation of the total phenolic compounds and anthocyanins during the alcoholic fermentation and on the spectral characteristics of Cabernet Sauvignon wines. The experiment was carried out with grapes of Cabernet Sauvignon variety with sugars content of $23.10 \%$ and titratable acids of $6.15 \mathrm{~g} / \mathrm{dm}^{3}$. The alcoholic fermentation was conducted with inoculum amount of yeast culture 2, 3 and 4\% of the strains Bordeaux and 8-11 of Saccharomyces cerevisiae species. The fermentation temperature was 20,24 and $28^{\circ} \mathrm{C}$. The course of the process was followed by the variation in the dry matter, measured daily with the Abbe refractometer. The dynamics of the total phenolic compounds and the anthocyanins during the fermentation was determined by measuring on $1^{\text {st }}, 5^{\text {th }}, 10^{\text {th }}$ and $20^{\text {th }}$ day. After the alcoholic and the malolactic fermentations in the experimental wines were also analyzed the content of flavonoid phenolic compounds, non-flavonoid phenolic compounds and their spectral characteristics. The results demonstrated that under the experimental conditions both strains Bordeaux and $8-11$ exhibited the best fermentation activity at $28{ }^{\circ} \mathrm{C}$. The temperature factor had a stronger impact on the variations of total phenolic compounds and anthocyanins in the course of the alcoholic fermentation. The quantitative maximum of both indicators was recorded on the $5^{\text {th }}$ day of the process. In the experimental wines, the variants fermented under the conditions of $28{ }^{\circ} \mathrm{C} / 4 \%$ contained more total phenolic compounds, anthocyanins, flavonoid phenolic compounds and nonflavonoid phenolic compounds. The red colour ratio also was the highest. The wines of 8-11 strain were distinguished by a higher content of total phenolic compounds, anthocyanins and, respectively a more intense colour.

Keywords: wine, yeast, alcoholic fermentation, phenolic compounds, spectral characteristics.

\footnotetext{
*Corresponding author: Tatyana Yoncheva, Institute of Viticulture and Enology, "Kala tepe" 1 , 5800 Pleven, Bulgaria $\triangle \pm$ ion@abv.bg
} 


\section{Introduction}

The wine characteristics have been determined by the variety potential and specificity, but also by the yeast strain carrying out the alcoholic fermentation. It has a significant influence on its composition with its metabolism and physiological features.

Phenolic components play a significant role in the formation of the organoleptic wine qualities, especially of red wines. The amount of phenolic compounds in grapes depended on number of factors, as the main of them being the variety, the soil and weather conditions in the growing area, the applied agricultural and technical practices, the degree of maturity, etc. Most of the phenolic compounds are contained in the seeds and the skins, from where they pass into the must and the wine (Abrasheva et al., 2003).

The wine anthocyanin profile has also been determined by the variety specifics (Burns et al., 2003; Otteneder and Marx, 2004). The anthocyanins are localized mainly in the grapes skin, in free or bound state in the form of glycosides (Singleton and Trousdate, 1992; Fisher and Strasser, 1999). The fermentation conditions and certain technological factors such as the time of contact with the solids, the temperature, the yeast strain, also influence the amount of phenols and anthocyanins in wine (Stoyanov et al., 2004).

In the production of red wines, with the increase of the alcoholic content during the fermentation, the extraction of phenolic and colouring substances is enhanced as the optimal temperature for this being $28-30{ }^{\circ} \mathrm{C}$ (Getov, 2002). The yeast affects the colour of the wine mainly with the extracellular $\beta$-glucosidase they produce. Strains with low $\beta$-glucosidase activity produce wines with higher anthocyanin content (Tsvetanov et al., 1994; Tsvetanov et al., 1995). The higher activity does not result in a direct decrease in their amount but it is directly related to their colouring ability, converting them into copolymerization aglycons (Spasov et al., 1998; Rodrigues et al., 2004). Part of the anthocyanins during the fermentation are adsorbed by the yeast cells, as well as in the oxidation, variations in the medium $\mathrm{pH}$, interacting with other substances and pass into insoluble form and precipitate (Chobanova, 2012). As a result, both quantitative and qualitative variations in the phenolic and anthocyanin composition of the wine are observed at the end of the process.

The objective of the study was to investigate the influence of the technological factors yeast strain, temperature and inoculum amount of yeast culture on the variation of the total phenolic compounds and anthocyanins during the alcoholic fermentation and on the spectral characteristics of Cabernet Sauvignon wines.

\section{Material and methodology}

\section{Plant material}

The experiment was carried out with grapes of Cabernet Sauvignon variety. Each technological variant was crumbled and crushed separately and by equal distribution of the grapes, it was ensured the uniformity of the raw material. 


\section{Alcoholic fermentation}

\section{Conditions}

The alcoholic fermentation was carried out under the following conditions:

- fermentation substrate $-4.0 \mathrm{~kg}$ of grape pulp, sulphuring with $50 \mathrm{mg} / \mathrm{kg} \mathrm{SO}{ }_{2}$, with sugars content of $23.10 \%$ and titratable acids of $6.15 \mathrm{~g} / \mathrm{dm}^{3}$;

- 48-hour active yeast culture of the Bordeaux and 8-11 collection strains of Saccharomyces cerevisiae species in quantity of $2 \%, 3 \%, 4 \%$ (the strains were provided by the yeast collection of the University of Food Technologies, Plovdiv, Bulgaria);

- fermentation temperature $-20^{\circ} \mathrm{C}, 24^{\circ} \mathrm{C}, 28^{\circ} \mathrm{C}$.

The course of the alcoholic fermentation was followed by the variation in the dry matter, measured daily by means of an Abbe refractometer at a constant value.

\section{Determining the variations in total phenolic compounds and anthocyanins}

The content of the total phenolic compounds and anthocyanins during the fermentation was determined, taking the following steps: start (day 1), vigorous fermentation (day 5), silent fermentation (day 10) and after the malolactic fermentation (day 20). Their amount was analyzed in the clear part, after centrifugation of the samples, using a UV-Vis spectrophotometer Cary 50 Varian, respectively by the methods:

- total phenolic compounds (TPC), g/ $\mathrm{dm}^{3}$ gallic acid - method of Singleton and Rossi with a Folin-Ciocalteu reagent and measurement of sample absorption spectrophotometrically at $\lambda 750 \mathrm{~nm}$ (Ivanov et al., 1979);

- anthocyanins, $\mathrm{mg} / \mathrm{dm}^{3}$ - method of Gayon and Stonestreet by $\mathrm{pH}$ changing and using of buffer solutions with pH 0.6 and $\mathrm{pH} 3.5$ and the absorption of both samples was measured spectrophotometrically at $\lambda 520 \mathrm{~nm}$ (Ivanov et al., 1979).

\section{Determination of the content of phenolic compounds, anthocyanins and spectral characteristics of the experimental wines}

After the end of the alcoholic fermentation (found by chemical analysis of the sugars) and the spontaneous malolactic fermentation (established by paper chromatography), the experimental wines were decanted and by UV-Vis spectrophotometer Cary 50 Varian, they were further analyzed for the content of:

- flavonoid phenolic compounds (FPC), $\mathrm{mg} / \mathrm{dm}^{3}$ catechin equivalent and non-flavonoid phenolic compounds (NPC), $\mathrm{mg} / \mathrm{dm}^{3}$ caffeic equivalent - Somers method with analytical and calculation part $-0.2 \mathrm{~cm}^{3}$ of the test sample was added to $10 \mathrm{~cm}^{3} 1 \mathrm{n} \mathrm{HCl}$ and between $3^{\text {rd }}$ and $4^{\text {th }}$ hour the absorbance of the solution was measured at 280 and $320 \mathrm{~nm}$ (Chobanova, 2007)

- spectral characteristics - determined by measuring the sample absorbance in a $0.1 \mathrm{~cm}$ cuvette at $\lambda$ 420, 520 and $620 \mathrm{~nm}$ and equated to a $1 \mathrm{~cm}$ cuvette (Chobanova, 2007):

- colour intensity IC' [abs. unit] - the Glories method, was the sum of the measurements at the three wavelengths:

$$
I C^{\prime}=A_{420}+A_{520}+A_{620}
$$


- colour tint $T$ [abs. unit] - the Sudraud method represented the absorbance at $420 \mathrm{~nm}$ and $520 \mathrm{~nm}$ ratio:

$$
T=A_{420} / A_{520}
$$

- $d A \%$ - the Glories method, the indicator expressed the participation of free and bound flavylium forms of anthocyanins in the total wine colour:

$$
d A \%=\left\{1-\left[\left(A_{420}+A 620\right) / 2 \times A_{520}\right]\right\} \times 100
$$

- yellow colour ratio in the total wine colour - the Glories method, absorbance measurement at $420 \mathrm{~nm}$ :

$$
\% \text { yellow colour }=\left(A_{420} / I C^{\prime}\right) \times 100
$$

- red colour ratio in the total wine colour - the Glories method, absorbance measurement at $520 \mathrm{~nm}$ :

$$
\% \text { red colour }=\left(A_{520} / I C^{\prime}\right) \times 100
$$

- blue colour ratio in the total wine colour - the Glories method, absorbance measurement at $620 \mathrm{~nm}$ :

$$
\% \text { blue colour }=\left(A_{620} / I C^{\prime}\right) \times 100
$$

\section{Results and discussion}

The investigation of the studied technological factors impact on the time of the alcoholic fermentation found that Bordeaux and 8-11 strains exhibited good fermentation activity. With the temperature and the inoculum amount of the yeast culture increase, within one temperature range, the process began and ended earlier. The dynamics of the dry matter in the fermentation of the grape pulp with both strains were similar. At $20^{\circ} \mathrm{C}$, the process started and ran more slowly, due to the slower cell multiplication. The yeasts exhibited the best activity at $28{ }^{\circ} \mathrm{C}$ and the duration of the process was shorter by 3-4 days compared to that at $20^{\circ} \mathrm{C}$. With the increase of the inoculum quantity of yeast culture $(2 \%, 3 \%, 4 \%)$ the fermentation occurred faster because of the higher number of active yeast cells in the medium.

The results of the dry matter variation during the fermentation of Cabernet Sauvignon grape pulp with the studied strains are presented in Figure 1.

In the course of the alcoholic fermentation, the variation of TPC and anthocyanins in the grape pulp was monitored. The results of their dynamics have confirmed the findings of other authors (Sims and Bates, 1994; Spranger et al., 1998), namely reaching the maximum during the exponential phase of yeast development followed by a decrease in their concentration due to the absorption by the cells or the involvement in the condensation processes. The effect of the inoculum amount of the yeast culture of the studied strains was similar and relatively weaker. The influence of the factor temperature was stronger as an indicator of the fermentation process. The higher temperature benefited the colouring matter extraction from 
the solids during the fermentation. The studied indicators from the grape pulp composition showed a tendency of going up with the increase of the yeast culture amount and temperature, reaching the maximum rates at $28{ }^{\circ} \mathrm{C} / 4 \%$.
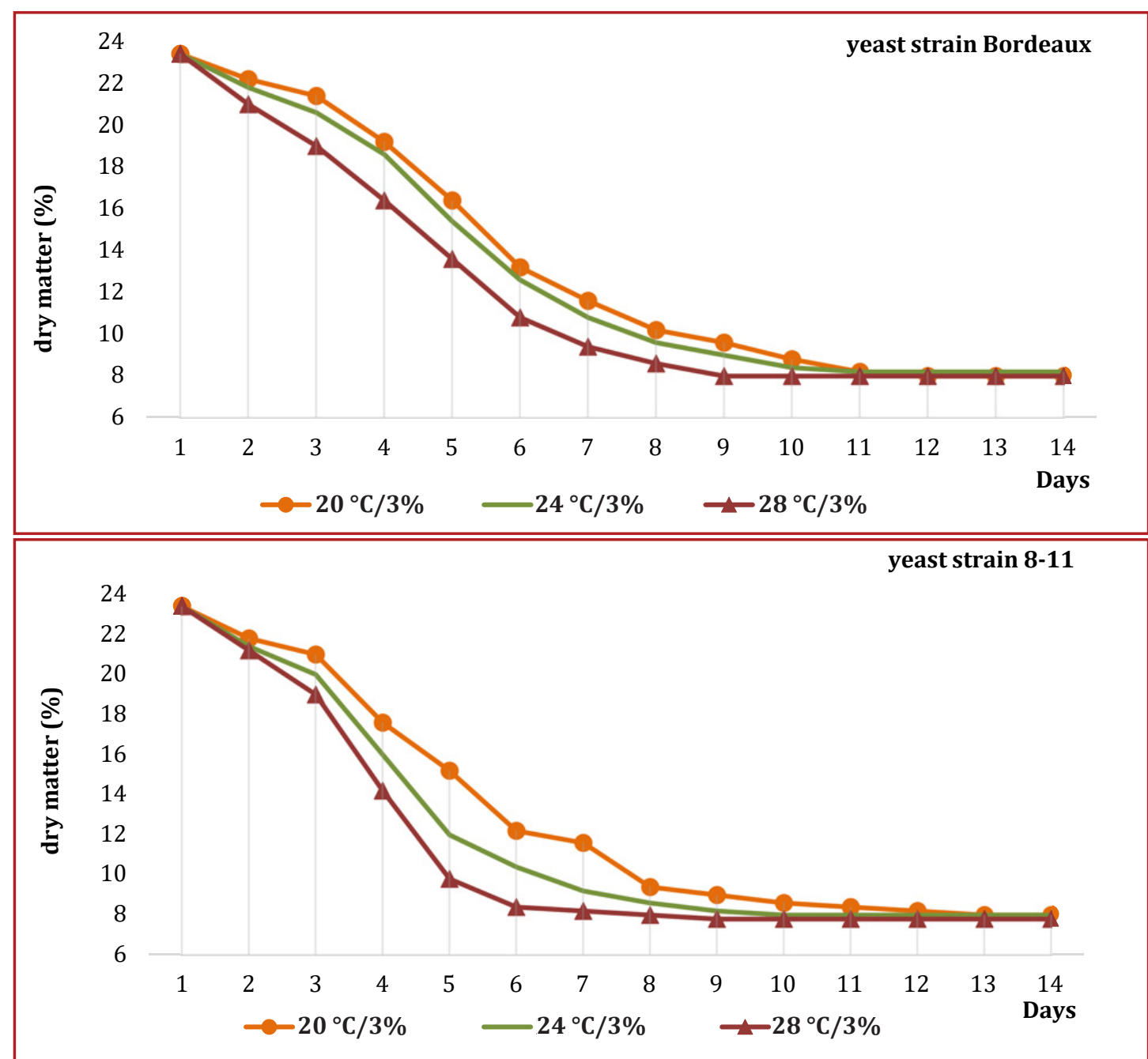

\footnotetext{
Figure 1 Dynamics of dry matter during the alcoholic fermentation of Cabernet Sauvignon grape pulp with the studied strains
}

Figures 2 and Figure 3 represent the variations in the TPC concentration and anthocyanins during the fermentation with Bordeaux and 8-11 strains at 3\% inoculum and temperature $20,24,28{ }^{\circ} \mathrm{C}$. The results of the process with 2 and $4 \%$ inoculum at the same temperature intervals were similar. 


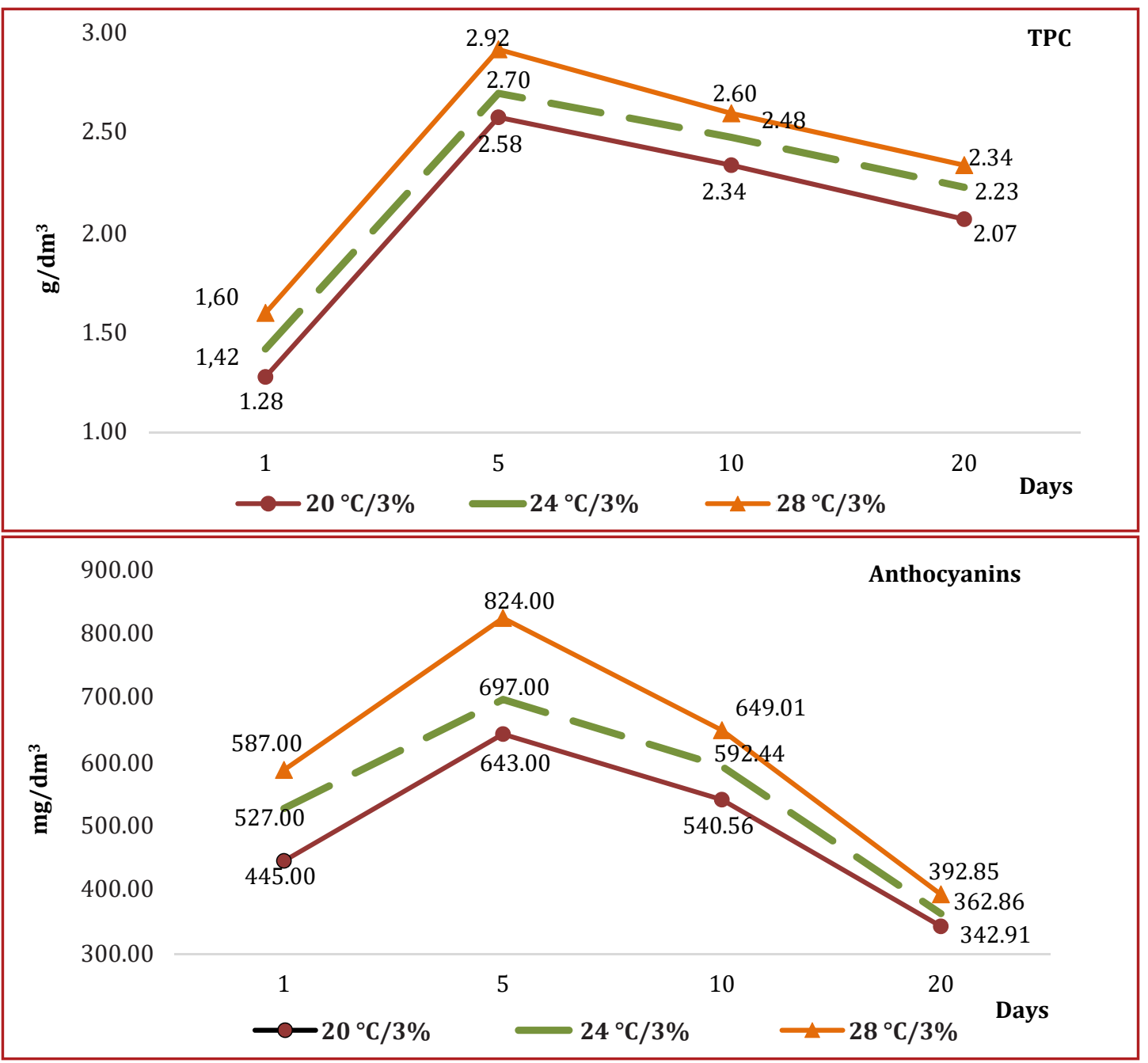

Figure 2 Variations in TPC and anthocyanins during the alcoholic fermentation with Bordeaux strain

The yeast effect appeared to be mainly on the amount of anthocyanins through the activity of the produced $\beta$-glucosidase. The Bordeaux strain had a higher $\beta$-glucosidase activity compared to the 8-11 strain (Yoncheva et al., 2007). Anthocyanins reduction during the fermentation was associated with the active cell development during the logarithmic phase, when cells released a significant amount of enzymes, including glucosidases, attacking their molecules (Kanev and Patokova, 2004).

The TPC and anthocyanins ratio was the highest for both strains, in wines fermented at $28{ }^{\circ} \mathrm{C}$. These results have confirmed that it was the optimal temperature for obtaining intensely coloured red wines with a high content of phenolic substances. The quantitative variation of anthocyanins during the fermentation indicated that the maximum was on the fifth day. In the conditions of the experiment at the same fermentation temperature, the amount of anthocyanins in the wines obtained with an inoculum of yeast culture 3 and 4\% was higher 
for both strains Bordeaux and 8-11. Due to the lower $\beta$-glucosidase activity of $8-11$ strain, the wines produced with it contained more anthocyanins.

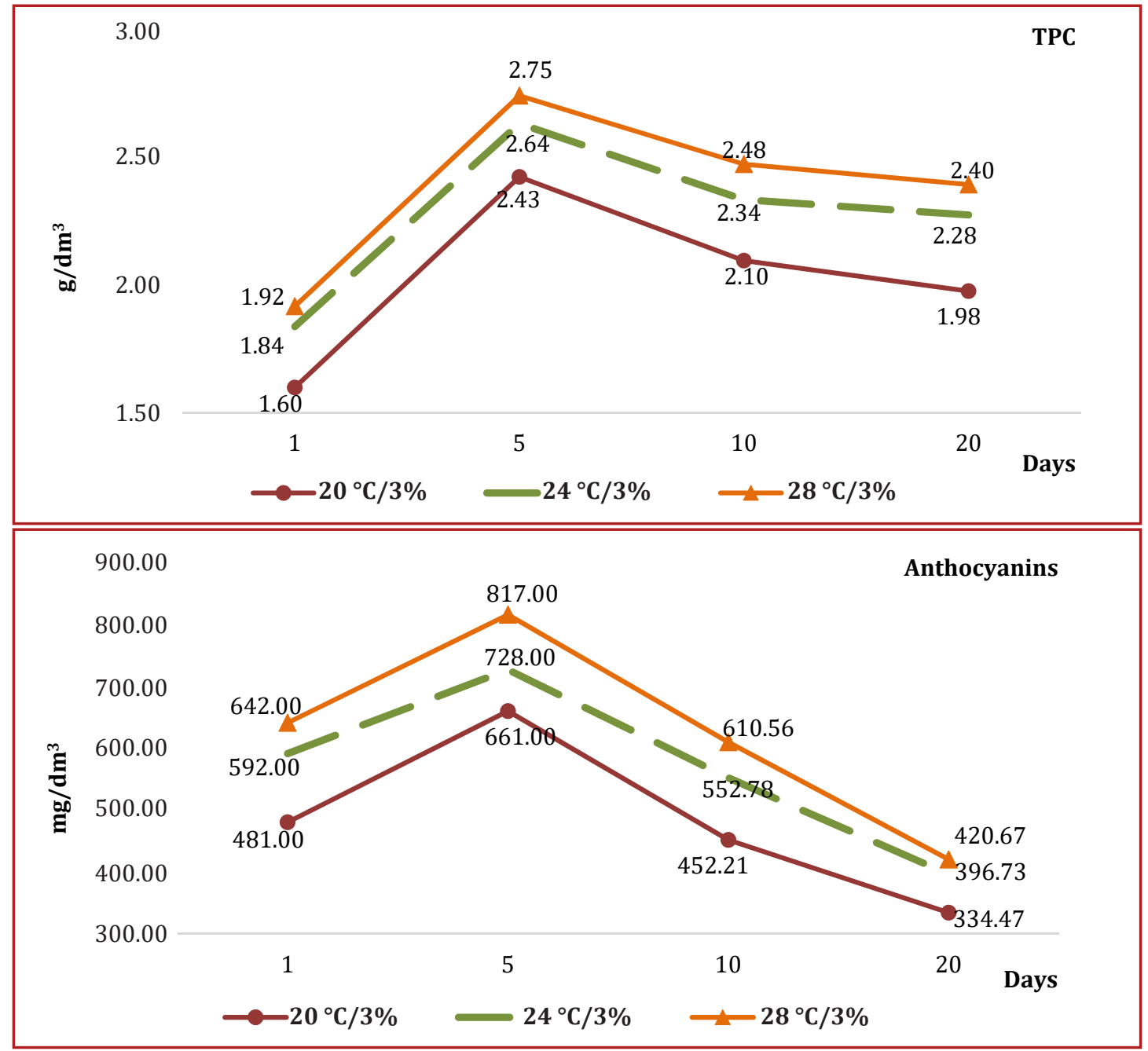

Figure 3 Variation in TPC and anthocyanins during the alcoholic fermentation with 8-11 strain

The rate of TPC in the experimental samples is proportional to that of the anthocyanins, so their variation in the course of the alcoholic fermentation was similar. In wines made with Bordeaux strain they ranged from $1.88\left(20{ }^{\circ} \mathrm{C} / 2 \%\right)$ to $2.38 \mathrm{~g} / \mathrm{dm}^{3}\left(28{ }^{\circ} \mathrm{C} / 4 \%\right)$, while in the samples obtained with $8-11$ strain - from $1.88\left(20{ }^{\circ} \mathrm{C} / 2 \%\right)$ to $2.44 \mathrm{~g} / \mathrm{dm}^{3}\left(28{ }^{\circ} \mathrm{C} / 4 \%\right)$.

This trend was similar for the obtained young wines - the variants fermented under the conditions of $28{ }^{\circ} \mathrm{C} / 4 \%$ contained more TPC, anthocyanins, as well as FPC and NPC (Table 1). That was due to the more intense extraction processes. The increase of FPC during the fermentation could be explained by the extraction from the solids and the rise in the amount of anthocyanins that were related to this group of compounds, while the higher rates of NPC 
were probably due to the formation of new phenolic acids during the sugars decomposition. Their concentration, however, did not reach such rates to affect negatively the wine quality.

Table 1 Phenolic compounds and spectral characteristics of the experimental Cabernet Sauvignon wines

\begin{tabular}{|c|c|c|c|c|c|c|c|c|c|}
\hline \multirow{3}{*}{$\begin{array}{l}\text { Variants } \\
\text { Indicators }\end{array}$} & \multicolumn{3}{|c|}{$20^{\circ} \mathrm{C}$} & \multicolumn{3}{|c|}{$24^{\circ} \mathrm{C}$} & \multicolumn{3}{|c|}{$28^{\circ} \mathrm{C}$} \\
\hline & $2 \%$ & $3 \%$ & $4 \%$ & $2 \%$ & $3 \%$ & $4 \%$ & $2 \%$ & $3 \%$ & $4 \%$ \\
\hline & \multicolumn{9}{|c|}{ Saccharomyces cerevisiae Bordeaux } \\
\hline $\mathrm{TPC}\left(\mathrm{g} / \mathrm{dm}^{3}\right)$ & 1.88 & 2.07 & 1.94 & 2.14 & 2.23 & 2.22 & 2.27 & 2.34 & 2.38 \\
\hline $\begin{array}{l}\mathrm{NPC}\left(\mathrm{mg} / \mathrm{dm}^{3} \text { caffeic }\right. \\
\text { equivalent) }\end{array}$ & 157.18 & 164.61 & 173.83 & 173.27 & 175.21 & 174.27 & 177.49 & 184.93 & 205.57 \\
\hline $\begin{array}{l}\mathrm{FPC}\left(\mathrm{mg} / \mathrm{dm}^{3}\right. \\
\text { catechin equivalent) }\end{array}$ & $2,935.77$ & $3,148.63$ & $3,270.06$ & $3,299.35$ & $3,559.36$ & $3,522.93$ & $3,672.24$ & $3,777.20$ & $3,790.79$ \\
\hline $\begin{array}{l}\text { Anthocyanins } \\
\left(\mathrm{mg} / \mathrm{dm}^{3}\right)\end{array}$ & 313.60 & 342.91 & 326.92 & 348.23 & 362.86 & 350.28 & 380.43 & 392.85 & 422.80 \\
\hline $\begin{array}{l}\text { Colour intensity IC' } \\
\text { [abs. unit] }\end{array}$ & 9.12 & 9.25 & 9.37 & 9.43 & 9.47 & 9.52 & 9.65 & 9.78 & 10.22 \\
\hline $\begin{array}{l}\text { Colour tint T } \\
\text { [abs. unit] }\end{array}$ & 0.476 & 0.465 & 0.473 & 0.470 & 0.389 & 0.477 & 0.516 & 0.545 & 0.512 \\
\hline dA \% & 70.10 & 70.40 & 69.60 & 69.80 & 68.20 & 69.70 & 67.00 & 66.10 & 66.70 \\
\hline$\%$ Yellow colour & 29.80 & 29.20 & 29.40 & 29.30 & 29.90 & 29.70 & 31.10 & 30.80 & 30.70 \\
\hline$\%$ Red colour & 62.60 & 62.80 & 62.20 & 62.30 & 61.10 & 62.20 & 60.30 & 60.00 & 60.00 \\
\hline \multirow[t]{2}{*}{$\%$ Blue colour } & 7.60 & 8.00 & 8.40 & 8.40 & 9.00 & 8.10 & 8.60 & 9.20 & 9.30 \\
\hline & \multicolumn{9}{|c|}{ Saccharomyces cerevisiae 8-11 } \\
\hline $\mathrm{TPC}\left(\mathrm{g} / \mathrm{dm}^{3}\right)$ & 1.88 & 1.98 & 1.91 & 2.10 & 2.28 & 2.25 & 2.22 & 2.40 & 2.44 \\
\hline $\begin{array}{l}\mathrm{NPC}\left(\mathrm{mg} / \mathrm{dm}^{3} \text { caffeic }\right. \\
\text { equivalent) }\end{array}$ & 164.50 & 173.16 & 172.50 & 181.26 & 179.15 & 196.69 & 195.58 & 194.93 & 208.90 \\
\hline $\begin{array}{l}\mathrm{FPC}\left(\mathrm{mg} / \mathrm{dm}^{3}\right. \\
\text { catechin equivalent) }\end{array}$ & $3,100.78$ & $3,047.92$ & $3,297.21$ & $3,295.06$ & $3,548.64$ & $3,609.35$ & $3,691.50$ & $3,711.50$ & $3,852.93$ \\
\hline $\begin{array}{l}\text { Anthocyanins } \\
\left(\mathrm{mg} / \mathrm{dm}^{3}\right)\end{array}$ & 310.36 & 334.47 & 328.28 & 372.48 & 396.73 & 388.15 & 385.68 & 420.67 & 424.94 \\
\hline $\begin{array}{l}\text { Colour intensity IC' } \\
\text { [abs. unit] }\end{array}$ & 9.48 & 9.50 & 9.54 & 9.78 & 10.20 & 10.85 & 11.12 & 11.65 & 11.86 \\
\hline $\begin{array}{l}\text { Colour tint T } \\
\text { [abs. unit] }\end{array}$ & 0.496 & 0.500 & 0.551 & 0.562 & 0.562 & 0.494 & 0.492 & 0.504 & 0.463 \\
\hline dA $\%$ & 68.80 & 68.50 & 65.20 & 63.10 & 64.40 & 67.90 & 68.60 & 67.30 & 71.30 \\
\hline$\%$ Yellow colour & 30.60 & 30.70 & 30.50 & 30.30 & 30.90 & 30.10 & 30.20 & 30.50 & 29.50 \\
\hline$\%$ Red colour & 61.60 & 61.30 & 60.90 & 60.50 & 60.40 & 60.90 & 61.50 & 60.40 & 61.20 \\
\hline$\%$ Blue colour & 7.80 & 8.00 & 8.60 & 9.20 & 8.70 & 9.00 & 8.30 & 9.10 & 9.30 \\
\hline
\end{tabular}

Note: TPC total phenolic compounds, FPC flavonoid phenolic compounds, NPC flavonoid phenolic compounds 
The wine composition rates and its spectral characteristics were within the typical ranges of Cabernet Sauvignon wines. With increasing the temperature and ratio of yeast culture, their amount went up due to the better extraction conditions. The highest rates were recorded in the variants fermented at $28{ }^{\circ} \mathrm{C}$ with $4 \%$ inoculum (Table 1). The wines of $8-11$ strain were characterized by a slightly higher content of TPC, anthocyanins and, respectively a more intense colour. The values of $\mathrm{dA} \%$ indicator, determining the brightness of the red colour were directly correlated with them. That affected positively the colour characteristics of the samples. The ratio of the three main colours was within the typical ranges for young red wines. The red colour share was the greatest in the variants obtained at $28^{\circ} \mathrm{C}$. The higher rate of the yellow colour in the samples of both strains resulted in a slight brick-coloured tinge, which was also confirmed by the tint values. That could be assumed as a prerequisite for the faster positive colour development during the wine aging.

\section{Conclusions}

Based on the study results it might be summarized:

- Bordeaux and 8-11 strains showed the best fermentation activity at $28{ }^{\circ} \mathrm{C}$. When increasing the inoculum amount of the yeast culture the fermentation also took place faster.

- The impact of the temperature on the variation of TPC and anthocyanins in the course of the alcoholic fermentation was more pronounced than the inoculum quantity of the yeast culture.

- The maximum concentration rate of TPC and the anthocyanins during the fermentation was recorded on the fifth day.

- In the experimental wines, the variants fermented at $28^{\circ} \mathrm{C} / 4 \%$ contained more TPC, anthocyanins, FPC, NPC and the share of the red colour was the highest.

- The wines of 8-11 strain had higher TPC content and because of the lower $\beta$-glucosidase activity of the strain they contained more anthocyanins and therefore had a more intense colour.

\section{References}

ABRASHEVA, P., BAMBALOV, K., GEORGIEV, A. 2003. Vine growing and Winemaking. Sofia : Publ. House "Matkom". ISBN 978-954-9930-50-4 (in Bulgarian).

BURNS, J., LANDRAULT, N., MULLEN, W., LEAN, M., CROZIER, A., TEISSEDRE, P. 2003. Variations in the profile and content of anthocyanins in wines made from Cabernet sauvignon and hybrid grapes. In Bulletin de l'O.I.V., vol. 76-865-866 (Mars-Avril), p. 263-280.

CHOBANOVA, D. 2007. Textbook for exercises in enology. Plovdiv : UFT Academic Publ. House. ISBN 95424-0082-9 (in Bulgarian).

CHOBANOVA, D. 2012. Enology. Part I: Composition of wine. Plovdiv : UFT Academic Publ. House. ISBN 978-954-24-0206-0 (in Bulgarian).

FISHER, U., STRASSER, M. 1999. Tanin management. Teil I. Von Körper, Fülle und Nachhatigkeit. In Das Deutsche Weinmagazin, vol. 18, p. 36-39 (in German).

GETOV, G. 2002. The influence of the fermentation temperature on the composition and the quality of red wines. In Anniversary scientific session with international participation "100 Years Institute of 
Viticulture and Enology, Pleven - 2002", Conference proceedings. Sofia : SPS PRINT, p. 337-343. ISBN 954-8217-17-1 (in Bulgarian).

IVANOV, T., GEROV, S., YANKOV, A., BAMBALOV, G., TONCHEV, T., NACHKOV, D., MARINOV, M. 1979. Practicum in wine technology. Plovdiv : Publ. house Hristo G. Danov (in Bulgarian).

KANEV, T., PATOKOVA, R. 2004. First results of a study on pre-fermentation and post-fermentation maceration in the production of red wines. In II Balkan Symposium of Viticulture and Enology, Pleven, Bulgaria, poster (in Bulgarian).

OTTENEDER, H., MARX, R. 2004. Method-performance study on the determination of nine characteristic anthocyanins in red wine by HPLC. In Bulletin de l'O.I.V., vol. 77-877-878 ( Mars-Avril), p. 255-274.

RODRIGUEZ, M., LOPES, C., BROOCK, M., VALLES, S., RAMON, D., CABALLERO, A. 2004. Screening and typing of Patagonian wine yeasts for glycosidase activities. In Journal of Applied Microbiology, vol. 96(1), p. 84-95. https://doi.org/10.1046/j.1365-2672.2003.02032.x

SIMS, C., BATES, R. 1994. Effects of skin fermentation time on the phenols, anthocyanins, ellagic acid sediment and sensory characteristics of a red Vitis rotundifolia wine. In American Journal of Enology and Viticulture, vol. 45(1), p. 56-62.

SINGLETON, V., TROUSDALE, E. 1992. Anthocyanin - tannin interactions explaining differences in polymeric phenols between white and red wines. In American Journal of Enology and Viticulture, vol. 43(1), p. 63-70.

SPASOV, H., KOCHEVA, E., BAMBALOV, V., BAMBALOV, K. 1998. Influence of the wine yeast on the colour of red wines. In Viticulture and Enology Journal, vol. 4, p. 13-15 (in Bulgarian).

SPRANGER, M., SUN, B., LEANDRO, M., CARVALHO, E., BELCHIOR, A. 1998. Changes in anthocyanins, catechins and proanthocyanidin during fermentation and early postfermentation of red grapes. In XXIII Congres Mondial de la Vigne et du Vin. Lisbonne, p. 183-188.

STOYANOV, N., KEMILEV, S., SPASOV, H., MITEV, P. 2004. Influence of the vinification regime on the degree of extraction of phenolic compounds from the solid grapes in the production of red wines. In Viticulture and Enology Journal, vol. 5, p. 21-27 (in Bulgarian).

TSVETANOV, O. et al. 1995. Selection of yeast for the production of red wines. In Viticulture and Enology Journal, vol. 5, p. 16-18 (in Bulgarian).

TSVETANOV, O., BAMBALOV, K., ANGELOVA, ZH. 1994. Dependence of the colour characteristics of red wines from the yeast strain. In Food Industry Magazine, vol. 8, p. 21-23 (in Bulgarian).

YONCHEVA, T., POPOVA, ZH., SPASOV, H., KOLEVA, A., MIHAYLOVA - MIKOVA, S. 2007. Study of $\beta$-glucosidase activity of wine yeast and its influence on red wine colour. In Scientific Conference with International Participation "Sustainable Development of Vine-Growing and Wine-Knowledge Based on Knowledge", Conference proceedings. Pleven : PRV-Refresh Vision, p. 272-278. ISBN 978954-2920-84-7 (in Bulgarian). 